${ }^{1}$ School of Dentistry, Faculdade São Leopoldo Mandic. Campinas, SP, Brasil.

${ }^{2}$ Department of Implantology, School of Dentistry, Universidade Santo Amaro. São Paulo, SP, Brasil.
Corresponding author:

Edelcio de Souza Rendohl Department of Implantology, School of Dentistry,

Universidade Santo Amaro, 340 Rua Prof. Enéas de Siqueira Neto, Jardim das Imbuias, São Paulo - SP, 04829-300, Brasil. Tel.: +55 0800171796, e-mail: edelcio.rendohl@gmail.com

Received: April 11, 2019

Accepted: August 23, 2019

\section{Influence of angulation and height of tooth preparation on the distribution of tensions in prosthetic crowns for upper central incisor: in silico analysis}

\author{
Marcos Teixeira Machado ${ }^{1}$, Edelcio de Souza \\ Rendohl2 ${ }^{2,}$, Karina Andrea Novaes Olivieri', Milton
} Edson Miranda ${ }^{1}$, William Cunha Brandt ${ }^{2}$

Aim: it was to use tridimensional finite element analysis (FEA) to analyze the effect of height and angulation of prosthetic preparations on the distribution of stresses for lithium disilicate prosthetic crowns, the underlying resin cement, and the prosthetic preparation of a superior central incisor. Methods: a CAD modeling software, SolidWorks 2013, was used to generate three-dimensional virtual models comprising the dimensions of the preparation parameters. Three angles (6, 12 and 16 degrees) were simulated on the prepared walls and two wall heights were utilized ( 4 and $5 \mathrm{~mm}$ ), for a total of six model groups according to the height and angulation of the walls. A vertical line in the $\mathrm{Y}$-axis was used as a reference for determining the degrees of convergence (inclination of the preparations). The chamfer finish and preparation width were standardized for all groups. Results: the $4 \mathrm{~mm}$ preparations behaved more appropriately when the axial wall convergence was approximately 6 degrees. The $5 \mathrm{~mm}$ preparations required 12 degrees of angulation. In relation to resin cement, there was better stress distribution when the angle of incisal convergence was between 6 and 12 degrees. An increase to 16 degrees led to a considerable increase in peak stress at the preparation margin. Conclusion: it was concluded that the convergence of the axial walls of coronal preparations with 4 and $5 \mathrm{~mm}$ heights should be 6 and 12 degrees, respectively, to avoid high tension spikes in the underlying resin cement.

Keywords: Dental prosthesis. Tooth preparation. Finite element analysis. 


\section{Introduction}

Ceramics are the materials that most mimic the natural tooth. Ceramics have excellent biocompatibility and high ability to replicate and restore coronal stiffness ${ }^{1}$. However, these materials are friable and susceptible to fractures ${ }^{2}$. Thus, repetitive occlusal loads, coupled with the geometry of the restorations, intensity, direction, and properties of the materials used, can cause their longevity to be altered².

Another important factor that influences the strength and durability of dental ceramics is the dental preparation, due to its relation with the distribution of stresses to the dental remnant and restoration ${ }^{3}$. According to Rosentritt et al. ${ }^{4}$, clinical failures in ceramic restorations occur mainly due to the geometry and the characteristics of the tooth preparation, such as the angle of preparation of the axial walls, finishing line of the preparation, internal adaptation, thickness of the cement, internal draw of the crown and possible occlusal variations.

The patterns of preparation used today were largely defined by studies carried out many years ago ${ }^{5}$ and with few recent modifications ${ }^{6}$. However, the properties of the materials used and the technology used to achieve those historical results differed from the materials currently used; therefore, further research and study on the ideal characteristics for a dental preparation are required. Mainly due to the increase of using metal free ceramic restorations, which have the ability to bond to the dental substrate.

Likewise, the ability of various ceramic systems to adhere to the dentin substrate has led to a reduced need for tooth preparation and, often, the original preparation principles are no longer followed as initially proposed. However, it is worth noting that retention and the stability of dental preparations remain important when performing clinical procedures, as they influence stress distribution and can decisively contribute to the longevity of prosthetic procedures ${ }^{7-9}$.

In general, dental preparations with lower angulation of axial walls are recommended. However, the height of dental preparation may influence the seating of the ceramic restorations, due to the impossibility of the resin cement flowing. In such cases, increased angulation of the dental preparation may be necessary 9 .

Several authors ${ }^{6,8-11}$ studied the angulation of axial walls of dental preparations. However, there has been no consensus in the literature on the interrelationship of height and angulation of axial walls and how these variables influence the distribution of stress in the dental preparation, resin cement, and prosthetic crown. Therefore, it is important to establish clinical protocols involving height and axial inclination to create an adequate distribution of stress in the tooth preparation, resin cement and the prosthetic crown of lithium disilicate, with a view on the longevity of ceramic restorations.

Therefore, the objective of this study was to evaluate the influence of the angulation and the height of the dental preparation on the mechanical behavior of lithium disilicate prosthetic crowns, the underlying resin cement, and the coronal preparation of a superior central incisor submitted to an oblique load on its palatal face. 


\section{Materials and Methods}

Three-dimensional virtual models comprising the preparation dimensions were generated using the CAD modeling software, SolidWorks (Dassault Systems Solid-Works Corp., Waltham, MA, USA). Three angles (6, 12 and 16 degrees) and two heights ( 4 and $5 \mathrm{~mm}$ ) were simulated for the prepared walls, totaling six models. A vertical line in the $\mathrm{Y}$-axis was used as the reference for determining the degrees of convergence (inclination of the preparations). A bevel edge, as well as the width of the preparation, was standardized for all groups in order to isolate only the factors under study (Figure 1).

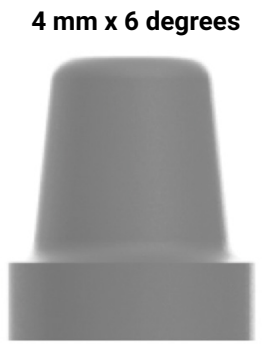

$5 \mathrm{~mm} \times 6$ degrees

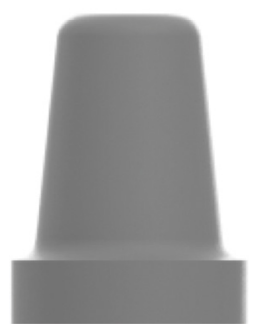

$4 \mathrm{~mm} \times 12$ degrees

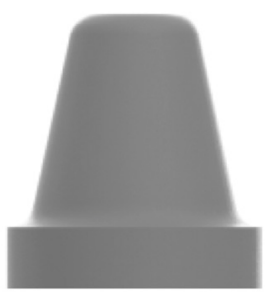

$5 \mathrm{~mm} \times 12$ degrees

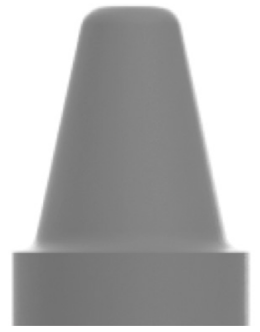

$4 \mathrm{~mm} \times 16$ degrees

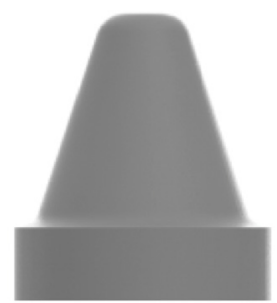

$5 \mathrm{~mm} \times 16$ degrees

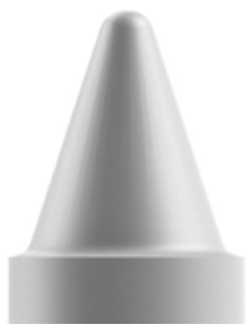

Figure 1. Preparations according to the height of the remnant.

With regards to simulating the resin cement, all faces of the preparation were converted to a zero thickness entity offset, which enabled a three-dimensional contour of the preparation. Thereafter, a thickening of $60 \mu \mathrm{m}$ was performed to simulate the cement layer. The behavior of the material was characterized during the subsequent phase of analysis.

For modeling the lithium disilicate crown, we used the anatomical dimensions of a central, maxillary incisor. Adjustments were made in the contours of the crown to fit in all the preparations, modifying only the internal region that was in contact with the preparation. The crown was positioned concentrically (both axes aligned) to the preparation and to the cement. The crown was adapted to the margin of the preparation, using the loft rebound tool, which enables copying the preparation margin and the margin of the crown to allow perfect adaptation between the two pieces. At this stage, the gaps and interference between the parts that could occur later during the 
analysis were verified. The crown was combined with the cementation line by means of boolean combination operations, which allowed the crown to be adapted to the cement and to the preparation. The set was exported to the Ansys Workbench software 14.0 (Ansys Inc., Canonsburg, PA, USA), to perform the mathematical analysis.

The characterization of the mechanical behavior of the materials was simulated based on data related to the modulus of elasticity and Poisson's coefficient, according to previously published works ${ }^{12-14}$. The data used are shown in Table 1.

Table 1. Modulus of elasticity and Poisson's coefficient of the materials used.

\begin{tabular}{lccc}
\hline Material & Modulus of elasticity & Poisson's coefficient & Reference \\
\hline Enamel & $84 \mathrm{GPa}$ & 0.30 & Ichim et al. (2007) \\
\hline Dentin & $18.6 \mathrm{GPa}$ & 0.31 & $\begin{array}{c}\text { Lin et al. (2006), Ozçelik \& } \\
\text { Ersoy (2007) }\end{array}$ \\
\hline Periodontal Ligament & $69 \mathrm{MPa}$ & 0.45 & \begin{tabular}{c} 
Ozçelik \& Ersoy (2007) \\
\hline Resin cement
\end{tabular} \\
\hline Lithium Dissilicate & $9.3 \mathrm{GPa}$ & 0.3 & $\begin{array}{c}\text { Lin et al. (2006), Ozçelik \& } \\
\text { Ersoy (2007) }\end{array}$ \\
\hline
\end{tabular}

The model was divided into small elements, which were interconnected through a mesh so that the software calculated the tensions generated in each piece. In the present study, a mesh of $0.50 \mathrm{~mm}$ tetrahedral elements was used. This type of element was selected because it is best suited to curved surfaces, as in the case of the tooth preparation. The number of nodes and elements obtained for each model are listed in Table 2. In addition, the model was fixed on both lateral sides so that displacement did not occur during load application. The simulation of masticatory contact occurred by applying a load of $100 \mathrm{~N}$ on the palatal surface of the crown, at a slope of 45 degrees (Figure 2). The data obtained were evaluated according to the von-Mises criterion for the crown and the preparation, as it shows active compression tensile stresses. The shear stress was used to evaluate the cement since this type of test is often used for evaluation of cement in "in vitro" research.

Table 2. Numbers of nodes and elements obtained for each model.

\begin{tabular}{|c|c|c|c|c|c|c|}
\hline & \multicolumn{3}{|c|}{$4 \mathrm{~mm}$ preparations } & \multicolumn{3}{|c|}{$5 \mathrm{~mm}$ preparations } \\
\hline & 6 degrees & 12 degrees & 16 degrees & 6 degrees & 12 degrees & 16 degrees \\
\hline Nodes & 24.139 & 24.085 & 23.077 & 25.637 & 25.280 & 24.279 \\
\hline Elements & 13.356 & 13.423 & 12.853 & 14.220 & 14.013 & 13.503 \\
\hline
\end{tabular}




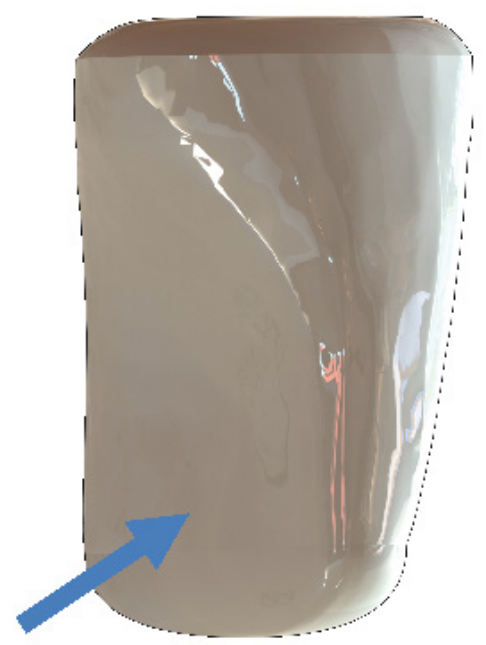

Figure 2. Application of loading site of $100 \mathrm{~N}$.

\section{Results}

The maximum stress values, expressed in MegaPascal (MPa), are shown in Table 3.

Table 3. The maximum stress value (expressed in MegaPascal - MPa) obtained.

\begin{tabular}{lcccccc}
\hline & \multicolumn{3}{c}{ 4 mm preparations } & \multicolumn{3}{c}{ 5 mm preparations } \\
\cline { 2 - 6 } & 6 degrees & 12 degrees & 16 degrees & 6 degrees & 12 degrees & 16 degrees \\
\hline $\begin{array}{l}\text { von-Mises } \\
\text { Crown }\end{array}$ & 197.9 & 250.26 & 247.26 & 243.83 & 220.31 & 227.78 \\
\hline Resin cement & 27.54 & 25.61 & 42.00 & 28.41 & 26.56 & 36.76 \\
\hline $\begin{array}{l}\text { von-Mises } \\
\text { preparation }\end{array}$ & 58.81 & 59.05 & 59.57 & 79.46 & 76.48 & 75.22 \\
\hline
\end{tabular}

With regards to the crown, an increase in stress concentration was observed when more convergence (12 and 16 degrees) was used in comparison to 6 degrees for the $4 \mathrm{~mm}$ preparations. The preparation of $4 \mathrm{~mm} \times 6$ degrees showed the lowest von-Mises tension value of the crown (197.9 MPa), while the 12 and 16-degree preparations presented values of 250.26 and $247.26 \mathrm{MPa}$, respectively. When the $5 \mathrm{~mm}$ preparation was used, 6 degrees of slope showed the highest values of tension (243.83 MPa), followed by 16 degrees (227.78 MPa) and 12 degrees (220.31 MPa). The peak of concentration was located where the crown met the chamfer margin. At this site, compression stress predominated due to the nature of the applied load (oblique loading) (Figure 3). 


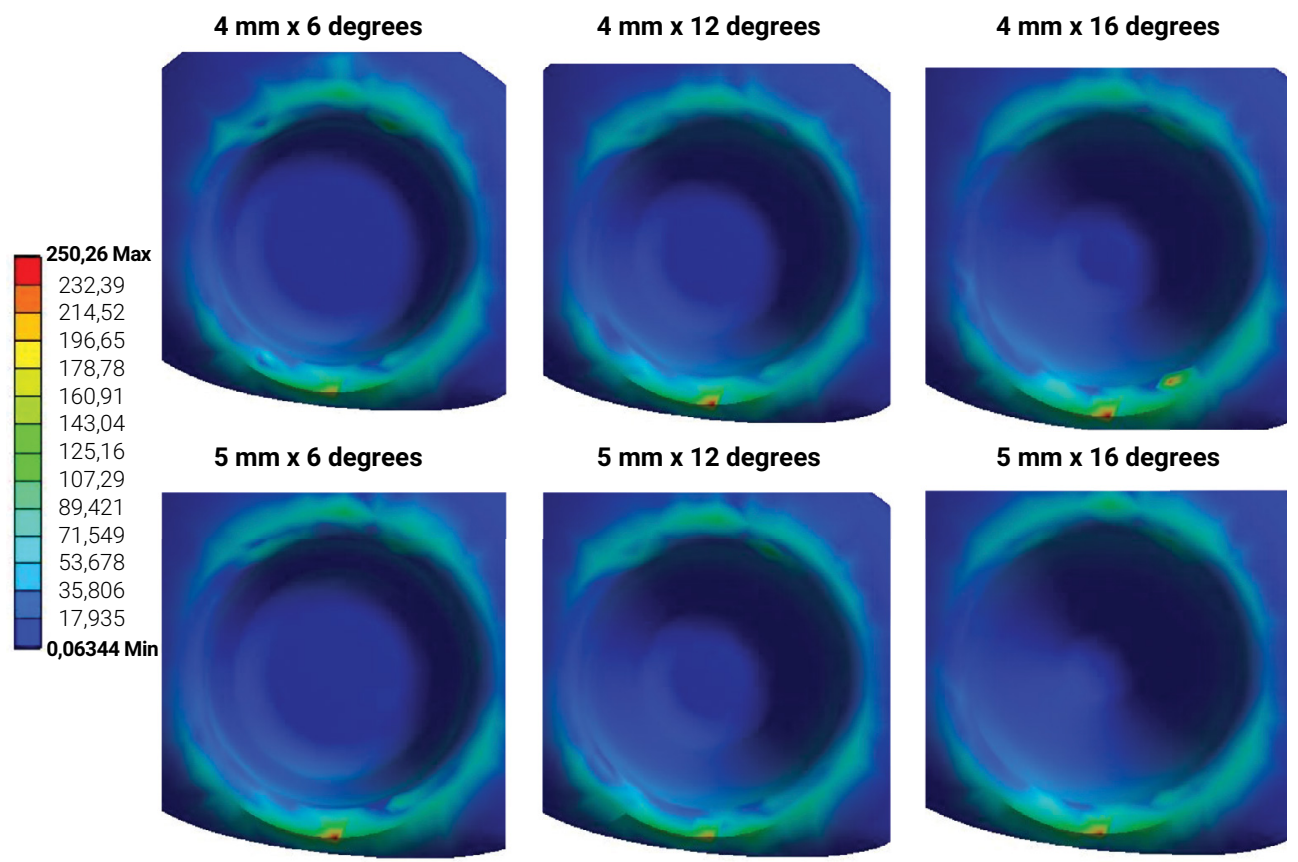

Figure 3. Shear stress in the prosthetic crown.

When analyzing the resin cement, the peak shear stress concentration was located at the cementation line near the margin with the prosthetic crown. For the $4 \mathrm{~mm}$ preparations, the 6 and 12-degree angles resulted in similar tension values of 27.54 and $25.61 \mathrm{MPa}$, respectively. The preparation for the 16-degree angle presented the highest value of tension, being distant of the other groups (42 MPa). For the $5 \mathrm{~mm}$ preparations, a similar behavior occurred, with shear stress values of $28.41 \mathrm{MPa}$ and 26.56 MPa for the 6 and 12-degree preparations, respectively. The $5 \mathrm{~mm} \times 16$-degree preparation produced the highest stress value of $36.76 \mathrm{MPa}$. For the 16 degrees angulation, the height increase decreased the tension values when comparing the $4 \mathrm{~mm}$ (42 MPa) and $5 \mathrm{~mm}$ (36.76 MPa) heights (Figure 4).

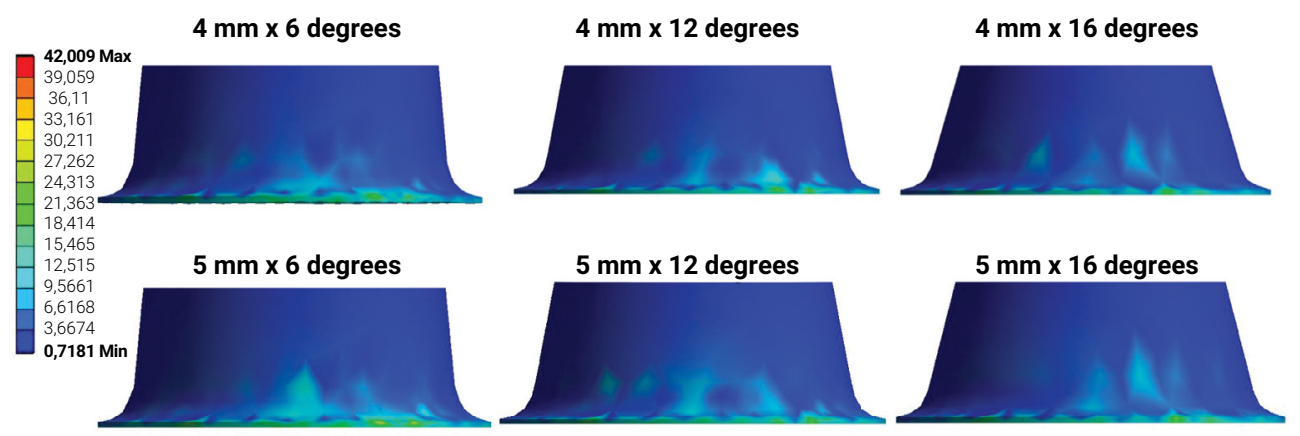

Figure 4. Shear stress in the cementation line. 
The von Mises strain values in the preparation were similar regardless of the height or angulation of the preparation. The peak stress concentration was located in the chamfer region, external to the transition region between the chamfer and the outer surface. The $4 \mathrm{~mm}$ preparations presented tension values of $58.81 \mathrm{MPa}, 59.05 \mathrm{MPa}$, and $59.57 \mathrm{MPa}$ for the 6, 12 and 16 degrees, respectively. For the $5 \mathrm{~mm}$ preparations, a similar behavior occurred with higher values when compared to the $4 \mathrm{~mm}$ preparations. The tensile values were 79.46 MPa, 76.48 MPa and 75.22 MPa for the 6, 12 and 16-degree preparations, respectively (Figure 5).

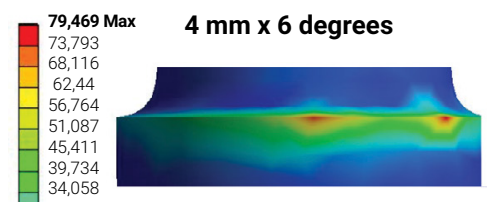

$5 \mathrm{~mm} \times 6$ degrees

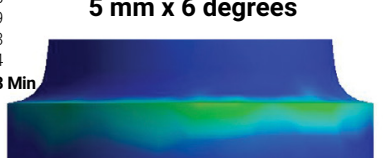

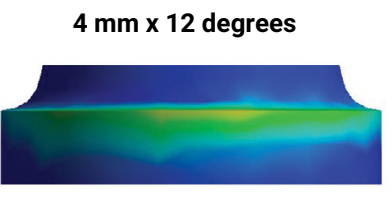

$5 \mathrm{~mm} \times 12$ degrees

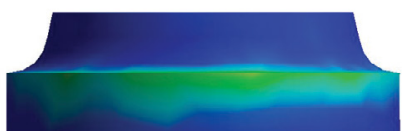

$4 \mathrm{~mm} \times 16$ degrees

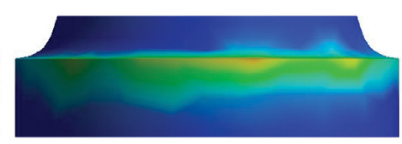

$5 \mathrm{~mm} \times 16$ degrees

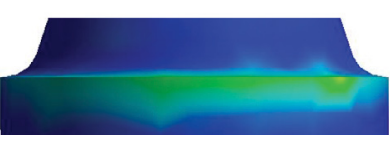

Figure 5. von-Mises stress for the preparation values.

\section{Discussion}

The methodology used in the present study (FEA) provided relevant explanations of how tensions behave in the prosthetic crowns of lithium disilicate, the underlying resin cement, and the actual preparation, especially as to the interrelationship that exists between the height of the preparations and the angles of convergence.

As shown in table 3, dental preparation tension has been higher due to the increase in the height of the preparation. This probably occurs because of the increased surface area in contact with the prosthesis. In addition, it has known that how lower convergence angle greater the retention and stability of the prosthesis, therefore, greater the initial tension?. These subjects also explain the fact of considering 4 and $5 \mathrm{~mm}$ preparations and the stress distributions in the lithium disilicate crowns, the results achieved adequate when the axial wall convergence was between 6 and 12 degrees.

The results showed that the increase of the axial inclination increases the tension, therefore 6 degrees would be the most indicated. However, the height of the tooth preparation (from 4 to $5 \mathrm{~mm}$ ) increased the surface area and allowed the axial inclination, it has also been showed to increase from 6 to 12 degrees. In fact, the use of axial inclination with 6 degrees showed the highest tension in the lithium disilicate crows when the height of $5 \mathrm{~mm}$ was performed. Due to the higher height of the clinical crown, bigger convergence angle should allow adequate cementation. The greater axial inclination is important as it can decrease the hydrostatic pressure on the cement at the cementation and to facilitate the complete settling the prosthesis to the tooth. 
The findings of the present study also agree with the results of Shillingburg et al. ${ }^{9}$, but those results were limited to an axial angulation of 6 degrees. Those authors concluded that this angulation would allow a better distribution of stresses in the underlying cement. Rosenstiel et al. ${ }^{6}$ likewise recommend an angle of 6 degrees to improve retention. Bowley and Kieser ${ }^{15}$ reached similar conclusions to those found in the present study, indicating that the axial inclination should not be greater than 10 degrees in crowns of 3 to $4 \mathrm{~mm}$ in height. Beuer et al. ${ }^{16}$ agreed that 12 degrees of convergence would be a good limit for total crowns, confirming the data of the present research. The works of Tiu et al. ${ }^{17}$ corroborate the present research, indicating a similar scope of axial angulation. However, according to Gilboe and Teteruck ${ }^{8}$, axial angulation must be limited between 2 and 5 degrees, which may be justified by the fact that those authors did not consider the height of the preparations and their interrelationship with the axial angulation in their conclusions.

Although the cited studies had similar results to this current research, they were performed using axial forces to evaluate retention and resistance, which does not simulate the functional components of the oral cavity. Thus, the oblique force at 45 degrees is the most appropriate for studies of tension in the buccal cavity, since its physical components can be decomposed into horizontal and axial forces, more naturally simulating the forces that occur on the tooth, as used in the present study. In addition, those studies based their conclusions only on the retention factor, without taking into account the stress distribution in the prosthetic crowns, the underlying cement, and the prosthetic preparation. Those studies also lack an evaluation of the interrelationships between the height and axial angulation of the preparations and the distribution of stresses during functional movements.

The axial angulation of 6 and 12 degrees is not accepted throughout the literature. Weed and Baez ${ }^{18}$ have suggested an angulation of 16 degrees for $3.5 \mathrm{~mm}$ preparations. However, the results of the present research showed that a slope of 16 degrees was undesirable for 4 and $5 \mathrm{~mm}$ preparations, as it induced an exaggerated increase of tensions in the underlying cement on the order of $61.5 \%$ and $33.7 \%$, respectively. It should also be noted that when these authors published their results, most of the fixed prostheses were cemented with zinc phosphate or glass ionomer cement, which have compression strength and tensions ranging from 3.1 $\mathrm{MPa}$ to $5.3 \mathrm{MPa}^{19}$. The level of stress concentration in the resin cement, at the preparation margins of $4 \mathrm{~mm}$ and 6 and 12-degree angulation, was 27.54 MPa and 25.61 MPa; while the concentration of the tensions in preparations of $5 \mathrm{~mm}$ and 6 and 12 degrees of axial angulation was 28.41 MPa and 26.56 MPa, respectively. These stress levels were already very high for the cementing agents used at that time. Thus, an increase of tensions on the order of $33.7 \%$ to $61.5 \%$ would make the prognosis of these prostheses even more critical if the axial inclination is increased to 16 degrees.

Additionally, Zidan and Ferguson ${ }^{20}$ concluded that retentive values for preparations with 24-degree convergence using adhesive resin cement had higher retention than cemented crowns with conventional cement and 6-degree axial convergence angles. However, these authors did not take into account the resistance of the resin cement to the tension, but only the retention obtained by the inclination of the axial walls. According to Lad et al. ${ }^{19}$, the resin cement showed a tensile strength of 34 to $41 \mathrm{MPa}$, 
according to the current results, a slope of 16 degrees and height of $4 \mathrm{~mm}$ presented $42 \mathrm{MPa}$, which exceeds the maximum resistance limit of the resin cement. Additionally, $5 \mathrm{~mm}$ preparations with 16 degrees of inclination produced tensions of $36.76 \mathrm{MPa}$. Thus, preparations with an angulation of 16 degrees or greater could lead to a failure of the cementing agent due to the excess tensions, especially in $4 \mathrm{~mm}$ preparations. Therefore, it would be important to establish a safety margin in the resin cement of at least $50 \%$ in their tensile strength in order to make the prosthetic procedures more secure, as well as to use appropriate protocols regarding the height and angulation of axial walls so as to provide better stress distribution.

Another factor that must be taken into account is the surface area of the preparation $^{21}$. According to Shillingburg Jr. et al.9, the larger the area of the cement fixed to the internal part of the restoration, the greater the retention. This factor partially explains why preparations with higher height allow greater angulation of the axial walls since they have a larger area of contact. Larger vertical walls increase the area of the preparation as well as the arc of rotation of the prosthetic crown, reducing the concentration of stresses in the cement of the preparation margins. The results of the current research corroborate the findings of Shillingburg Jr. et al. ${ }^{9}$; however, new studies should be proposed to evaluate the relationship between the surface area and the height of the preparation.

Therefore, based on the findings of the present study, prosthetic preparations with 4 and $5 \mathrm{~mm}$ high walls should limit the angulation of the axial walls to 6 and 12 degrees respectively, in order to avoid overloading the underlying cement, which may lead to a decrease in the survival rates of prostheses. However, it is worth emphasizing that the reality found in clinical practice does not always respect the desired axial inclination 22,23 .

According to the present research, the critical point to be observed in the distribution of tensions in fixed prosthodontics is found in the underlying resin cement. Therefore, it is recommended to limit the inclination of the axial walls of the coronal preparations of 4 and $5 \mathrm{~mm}$ in height to 6 and 12 degrees, respectively, to avoid high tension spikes which could lead to a failure in the prosthetic treatment.

\section{References}

1. Magne P, Belser U. Bonded porcelain restorations in the anterior dentition: a biomimetic approach. Carol Stream: Quintessence Publishing; 2002.

2. Zhang, Y., Sailer, I., Lawn, B.R., 2013. Fatigue of dental ceramics. J Dent. 2013 Dec;41(12):1135-47. doi: 10.1016/j.jdent.2013.10.007.

3. Oyar P, Ulusoy M, Eskitascioglu G. Finite element Analysis of stress distribution of 2 different tooth preparation designs in porcelain- fused-to-metal crowns. Int J Prosthodont. 2006 JanFeb;19(1):85-91.

4. Rosentritt M, Steiger D, Behr M, Handel G, Kolbeck C. Influence of substructure design and spacer settings on the in vitro performance of molar zirconia crowns. J Dent. 2009 Dec;37(12):978-83. doi: 10.1016/j.jdent.2009.08.003. 
5. Prothero JH. Prosthetic dentistry. Chicago: Medico-Dental Publishing; 1923.

6. Rosenstiel SF, Land MF, Fujimoto J. Contemporary fixed prosthodontics. Saint Louis: Mosby Elsevier; 2016.

7. Rekow ED, Harsono M, Jadal M, Thompson VP, Zhang G. Factorial analysis of variables influencing stress in all-ceramic crowns. Dent Mater. 2006 Feb;22(2):125-32.

8. Gilboe DB, Teteruck WR. Fundamentals of extracoronal tooth preparation.Part I. Retention and resistance form. J Prosthet Dent. 1974 Dec;32(6):651-6.

9. Shillingburg Jr HT, Jacobi R, Brackett SE. Fundamentals of tooth preparations for cast metal and porcelain restorations. Chicago: Quintessence books; 1987.

10. Goodacre CJ, Campagni WV, Aquino SA. Tooth preparations for complete crowns. An art form based on scientific principles. J Prosthet Dent. 2001 Apr;85(4):363-76.

11. Goodacre CJ. Designing tooth preparations for optimal success. Dent Clin North Am. 2004 Apr;48(2):v, 359-85.

12. Ichim I, Schmidlin PR, Kieser JA, Swain MV. Mechanical evaluation of cervical glass-ionomer restorations: 3D finite element study. J Dent. 2007 Jan;35(1):28-35.

13. Lin CL, Wang JC, Kuo YC. Numerical simulation on the biomechanical interactions of tooth/implant-supported system under various occlusal forces with rigid/non-rigid connections. J Biomech. 2006;39(3):453-63.

14. Ozçelik T, Ersoy AE. An investigation of tooth/implant-supported fixed prosthesis designs with two different stress analysis methods: an in vitro study. J Prosthodont. 2007 Mar-Apr;16(2):107-16.

15. Bowley JF, Kieser J. Axial-wall inclination angle and vertical height interactions in molar full crown preparations. J Dent. 2007 Feb;35(2):117-23.

16. Beuer F, Edelhoff D, Gernet W, Naumann M. Effect of preparation angles on the precision of zirconia crown copings fabricated by CAD/CAM system. Dent Mater J. 2008 Nov;27(6):814-20.

17. Tiu J, Al-Amleh, B, Waddell JN, Duncan WJ. Reporting numeric values of complete crowns. Part 1. Clinical preparations parameters. J Prosthet Dent. 2015 Jul;114(1):67-74. doi: 10.1016/j.prosdent.2015.01.006.

18. Weed RM, Baez RJ. A method for determining adequate resistance form of complete cast crown preparations. J Prosthet Dent. 1984 Sep;52(3):330-4.

19. Lad PP, Kamath M, Tarale K, Kusugal PB. Practical clinical considerations of luting cements: a review. J Int Oral Health. 2014 Feb;6(1):116-20.

20. Zidan O, Ferguson GC. The retention of complete crowns prepared with three different tapers luted with four different cements. J Prosthet Dent. 2003 Jun;89(6):565-71.

21. O'Kray H, Marshall TS, Braun TM. Supplementing retention through crown/preparation modification. An in vitro study. J Prosthet Dent. 2012 Mar;107(3):186-90. doi: 10.1016/S0022-3913(12)60054-7.

22. Parker MH, Malone $\mathrm{KH} 3^{\text {rd }}$, Trier AC, Striano TS. Evaluation of resistance form for prepared teeth. J Prosthet Dent. 1991 Dec;66(6):730-3.

23. Ghafoor R, Rahman M, Siddiqui AA. Comparison of convergence Angle of prepared teeth for full veneer metal ceramic crowns. J Coll Physicians Surg Pak. 2011 Jan;21(1):15-8. doi: 01.2011/JCPSP.1518. 